\title{
Optimization of the Structural Design of Transmission Tower Based on Simultaneous Topographical Algorithm and Structural Analysis Strategies
}

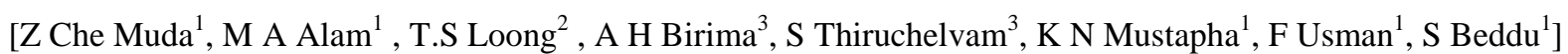

\begin{abstract}
Optimization of transmission tower structures is traditionally based on either optimization of members sizes with fixed topographical shape or based on structural analysis modelling strategies without taking cognizance of fabrication and constructability issue facing the contractors. This paper look into an integrated optimum design approach strategies whereby topographical factor is simultaneously integrated with the structural modelling strategy using truss and truss-beam analysis taking cognizance of fabrication cost in the construction of the transmission tower. The topographical algorithm is based on changing the inclination degree of the legs of the tower initially with optimum individual members sizing and structural modelling strategies. There after rationalized member sizes are performed through member groupings for the ease fabrication and construction of the transmission tower. First the weight optimizations on individual members are computed and designed to achieve the least weight of the overall structure using the truss and truss-beam modelling strategies. Subsequently the individual members are group as member grouping to achieve the the optimum fabrication in terms of cost and ease of fabrication of the tower. The optimum weight using topographical algorithm obtained for the transmission tower is $10,924 \mathrm{~kg}$ for singular members and $18,430 \mathrm{~kg}$ for element grouping at $10^{\circ}$ inclination angle after taking due cognizance of foundation loadings and deflections. Optimum design based on topographical algorithm for fabrication cost and ease of construction play a crucial role in the sustainable design and construction of the power transmission tower structures.
\end{abstract}

Keywords-optimization, topographical algorithm, transmission tower, structural analysis, modelling.

\section{Introduction}

In many countries, the usual methods of structural analysis of steel transmission towers tend to assume a simple truss behaviour where all the steel element connections are considered hinged. However the actual structure stability is related more to semi-rigid connections instead of the assumed hinged connections.

An alternative structural analysis modelling strategy for the steel tower design will be developed de-picting the asbuilt structural behaviour based on the least conservative approach that is in compliance with the design code of practice. This analysis modelling strategy with optimal least-weight design will be encapsulated in topographical shape environment which can be adopted in practice.

There is a great need to review the existing design processes, primarily those related to the analysis modelling strategy

${ }^{1}$ Centre of Forensic Engineering, Universiti Tenaga Nasional, Malaysia

${ }^{2}$ Student, Universiti Tenaga Nasional, Malaysia

${ }^{3}$ Centre of Sustainable Technology and Environment, Universiti Tenaga

Nasional, Malaysia

${ }^{4}$ Centre of Innovation and Design, Universiti Tenaga Nasional,,Malaysia with the aim of reducing the construction cost of the transmission tower.

Optimization of the transmission tower has become the main concern due to the escalating cost of steel. Designer of transmission tower are having a common aim to develop an efficient way to design a cost effective and optimized transmission tower. It is almost an impossible task to optimize the structures by trial and error method, even by an experience designer, where convergence can be achieve in compliance with the optimum member sizes (size is a variable factor), shape factor (structural coordinates is a variable) in conjunction with different structural analysis modelling strategies.

The main objective of this paper is to optimize the transmission steel tower design based on integrated approach combining simultaneously the size factor (member sizes is the variable), shape topography factor (tower shape is the variable) and structural analysis modelling strategies. The aim of this paper is to integrate three different variables which are the size, shape topography and optimum structural analysis modelling.

The topography shape algorithms involve a variable inclination angle of the tower generated by the user with automatic generation of its nodal coordinates. The legs of the transmission will be the main focus of weight saving as it constitutes up to $70 \%$ of the total weight of $32 \mathrm{~m}$ height $132 \mathrm{kV} 23 \mathrm{~T}$ TNB corner Transmission Tower.

It is envisaged in future that the design process will be based on an integrated optimum design approach that can both integrate size and shape algorithm with various structural analysis modelling to achieve the best weight optimization for the transmission tower.

Several studies on the structural assessment module of current steel design models for transmission and telecommunication towers have been carried out [1] and [2]. Optimum design module has been studied [3], [4] and [5]. Simultaneous optimization for both sizing and topographical algorithm of the Transmission Tower has been studied by das Neves and da Fonseca [6] Shape optimization of trusses has been carried out by M.P. Saka [7]. A review paper on numerical methods for shape optimization has been given by G. N Vanderplaats [8]. Rajan S.D developed a genetic algorithm that optimizes sizing, shape and topology variables in a truss using a genetic algorithm [9]. Zakaria Che Muda et al has developed a topographical algorithm based on the shape factor for the transmission tower leg [10]. It is critical to develop the design process that integrates both the topographical algorithm and structural analysis strategies to produce sustainable design of transmission tower structures. 


\section{Methodology}

\section{A. Topographical Algorithm}

The selection and development of a topographical algorithm to alter the leg coordinates of the tower is based on the legs inclination angle of the tower. The Visual Basic is use to develop as a pre-processor interface shape algorithm program. The angle in the shape algorithm program is defined by the user where the $3 \mathrm{D}$ coordinates are generated automatically and save as STAAD PRO input file. STAAD Pro program is used for optimization of sizes using truss or combined beam-truss structural analysis. This phase of topographical algorithm development is to alter the 3D coordinates of the original transmission tower automatically with a new set of coordinates based on the user preset inclination angle of the legs.

\section{B. Structural Analysis Modelling Strategies}

Structural modelling analysis strategies for the Transmission Tower are based on truss analysis or combined beam-truss analysis. In the combined beam-truss analysis, all the vertical member of the tower behave as a beam elements whilst all the other the horizontal and incline members act as a truss members. Sizes optimization on individual members or grouping is then carried out in STAAD Pro. The weight optimization using the analysis modelling strategies is then compared for each shape algorithm. The optimized weights are then obtained for the integrated three different variables which are the size, shape topography and optimum structural analysis modelling.

\section{Program Chart}

The flow chart in Fig. 1 of the interface space algorithm program is written in Visual Basic with Staad Pro. The user start the program and enter the desired inclination angle of the leg, The space algorithm program will extract the .std input file from the STAAD Pro and alter the co-ordinate automatically in accordance with the user define inclination angle of the leg as shown in Figure 1. Analysis has been done for both the truss element and combined beam-truss element analysis. Optimum member sizes are then obtained from both analyses based on grouping or individual member for the said inclination angle of the leg. A series of inclination angle then can be set to obtain the most optimum weight based on the inclination angle and above method of structural analysis.

\section{Discussion}

\section{A. Topographical Optimization of Transmission Tower}

In this project, the variable to alter the shape of the Transmission Tower is the angle of the Transmission Tower. Figure 2 shows the process where the analysis started by setting the new inclination angle of the leg of a transmission tower. The usual process of shape optimization might generate distortions of the finite element mesh, creating bad convergence in the solution of the problems [11].

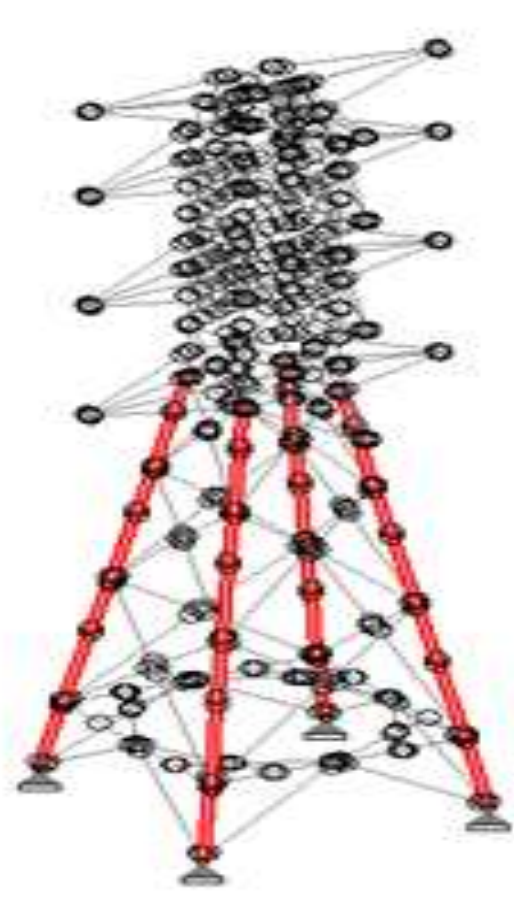

Figure 1 Discretization of the Tower

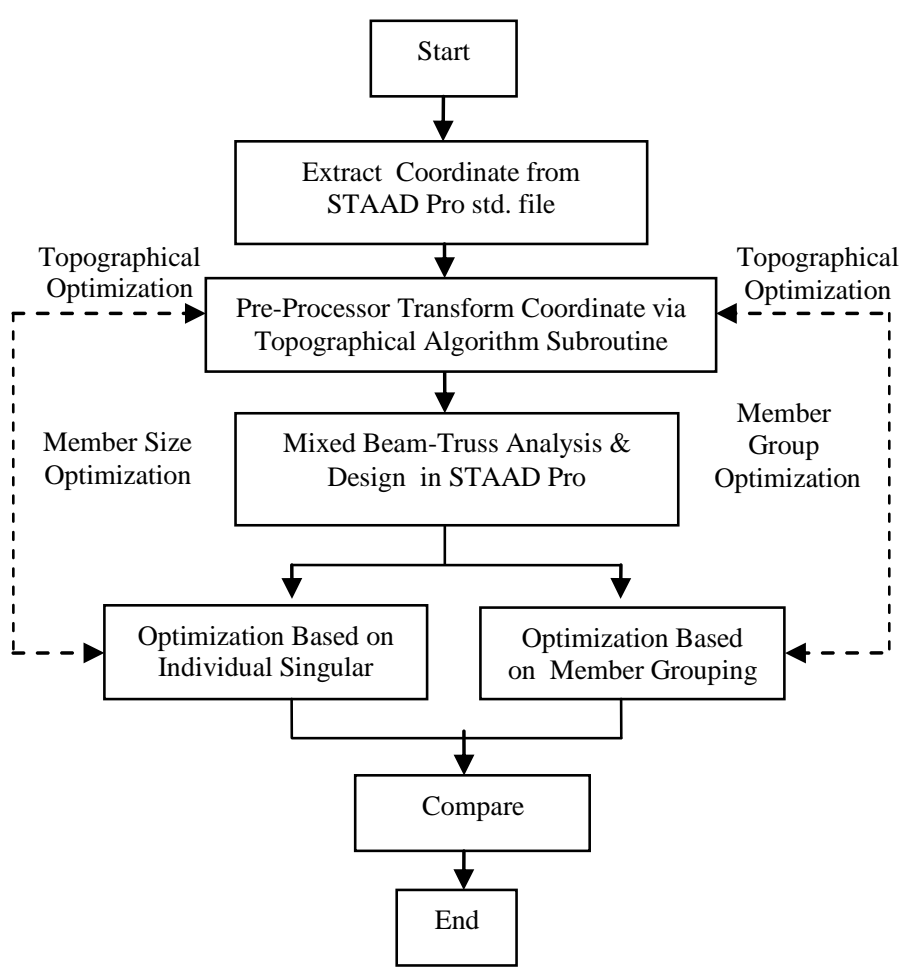

Figure 2 Flow Chart of Topographical Algorithm Interface with STAAD Pro 


\section{B. Loading Trees}

Combination of loads have be considered and as-signed because practically, the tower will not only face one type of load but a combination of several load which consists wind load, self-weight and the load from each condition of the loading trees.

There are four combinations of load shown in Fig. 3 to Fig. 6. Firstly, the combination 1 is wind load, self-weight and normal condition. Second, the combination 2 is wind load, self-weight and ground wire broken. As for the third combination is wind load, self-weight, top conductor and middle conductor broken and lastly, it is the combination 4 of wind load, self-weight, middle conductor and bottom conductor broken or top conductor and bottom conductor broken. The factor of safety will be included for each load which is 1.0 for self-weight, 1.25 for wind load, 2.5 for normal condition and 1.25 for broken condition.

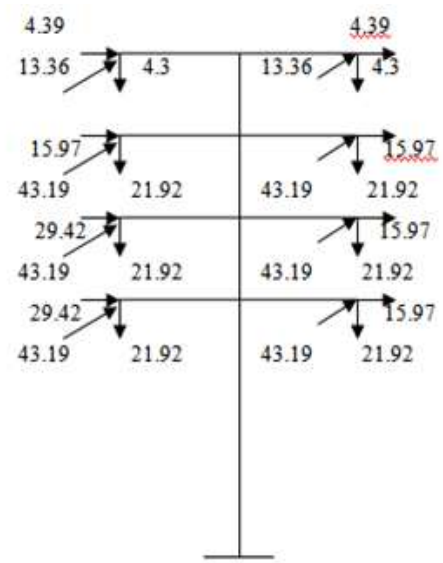

\section{(NORMAL CONDITION)}

Figure 3 - Load Combination 1

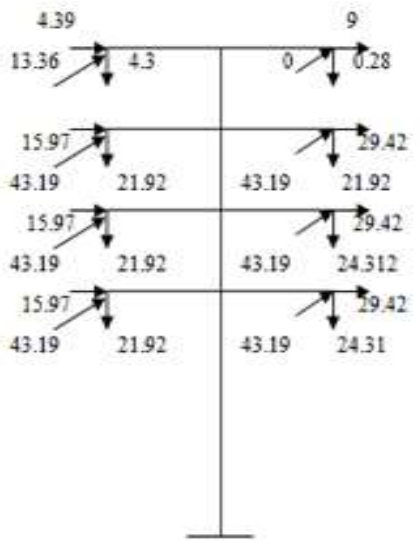

\section{(G.W. BROKEN)}

Figure 4 Load Combination 2

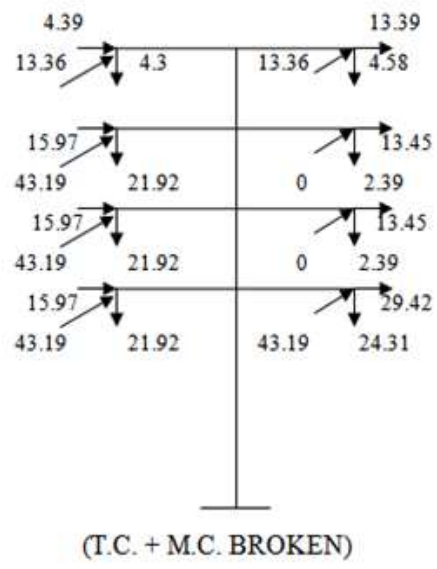

Figure 5 Load Combination 3

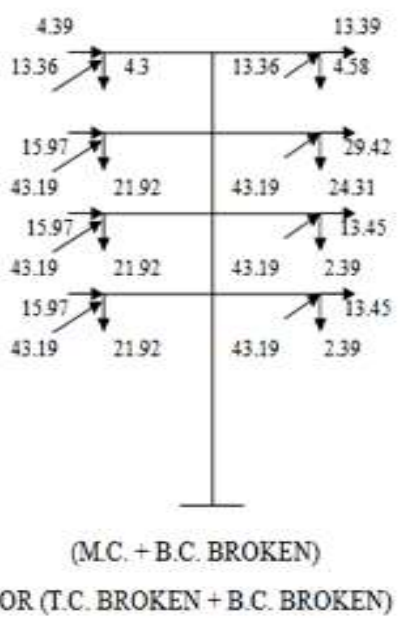

Figure 6 - Load Combination 4

In this case, the application of shape factor in this project is to alter the angle of the leg of the Trans-mission Tower as shown in Fig. 7. The user inter-face to set up the new inclination of the transmission tower's leg is shown in Fig. 8 .

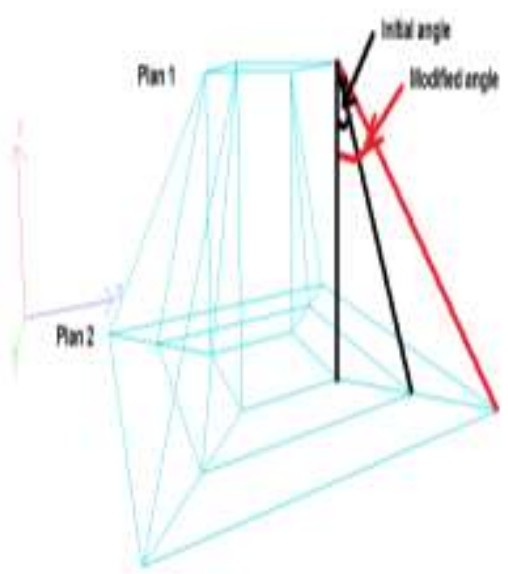

Figure 7 Leg Angle Shape Optimization 


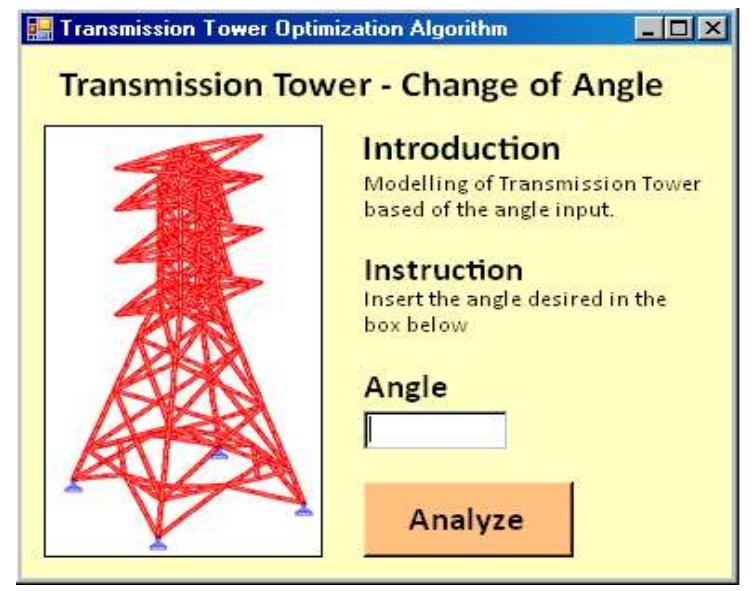

Figure 8 -Topographical Interface Program using Graphic User Interface

\section{iv. Structural Analysis Strategies}

\section{A. Truss Element Analysis}

The traditional methods used for structural analysis of steel structure which includes transmission tower assume the whole tower as a simple truss behaviour, where all the connections are considered as hinged. This will lead to the occurrence of unwanted degrees of freedom. Hence, the usual modelling of steel truss tower, the presence of connection will associated with the used of spatial truss finite element. The used of spatial truss finite element is presented in the Figure 9. Analysis shown that no matter is the Truss Element Analysis or the Combined Beam and Truss Analysis is used to analyze the steel structure, the lateral displacement values were not significantly changed.

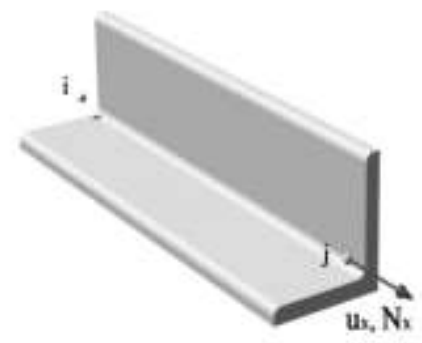

Figure 9 Spatial Truss Finite Element

Hence, to overcome this problem, dummy elements, with associated low axial stiffness values, are introduced into the structure. In this process every new bar represents the suppression of an internal degree of freedom

\section{B. Combined Beam and Truss Analysis}

Combined Beam and Truss Analysis is a modelling strategy combining beam and truss elements. The main structure will use spatial beam elements, as shown in Figure 10 , while the bracing system will use truss finite elements.

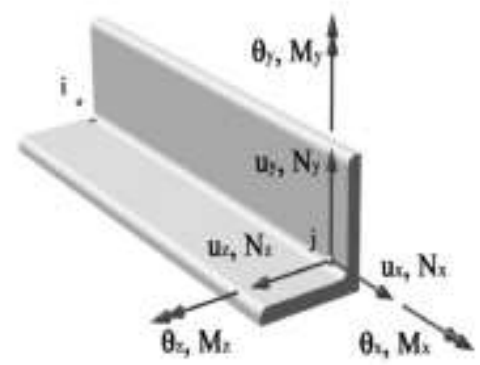

Figure 10 - Spatial Beam Finite Element

Beam finite elements are used for all the main members (vertical members) due to the rigid connections behaviour where a series of multiple bolts are used at the joints. Truss finite elements are still used in the bracing system because of two reasons. First, one bolt is usually used to connect the braced system to the main structural system. Second, the low flexure stiffness values associated to the secondary bracing elements implies that no significant moments will presented or transmitted to these structural members. This mixed modelling strategy can produce more realistic structural behaviour with respect to making it as close as possible to the actual built-up structure. Despite the numerous advantages related to the use of beam finite elements its exclusive adoption for modelling the investigated steel tower should be carefully evaluated.

\section{Integration of Shape Algorithm with Structural Analysis Strategies}

The designer should bear in mind that if rigid connections (beam element) were used in the design model, higher buckling load values would be pro-duced thus overestimating the actual values. Combined Beam and Truss Analysis thus produced slightly conservative values than the usual Truss Element Analysis. Analysis shown that either the Truss Element Analysis or the Combined Beam and Truss Analysis are used to analyze the steel structure; the lateral displacement values were not significantly changed.

In this paper, the software is tested for 5 different inclination angle of the leg of transmission tower. The inclination angles are set at $5^{\circ}, 10^{\circ}, 15^{\circ}, 20^{\circ}$ and $30^{\circ}$. The summary of the result is given in TABLE 1 .

Generally, optimization based on individual member generates the least weight however practical consideration for fabrication cost requires grouping of members. As for the optimization based on grouping the weight generated is base on optimum requirements for both weight and fabrication cost. Thus the grouping weight lies in between the initial and the optimized individual or singular members.

There is no significant difference in weight for both singular and grouping members for truss analysis compared with the combined truss-beam analysis strategies. As such we don't see any clear advantage of using the mixed truss beam design in terms of weight saving except that the modelling will depict the actual structural behaviour and no dummy elements are required as required in truss analysis. 
Proc. of the Third Intl. Conf. on Advances in Civil and Structural Engineering - CSE 2015

Copyright (c) Institute of Research Engineers and Doctors, USA .All rights reserved.

ISBN: 978-1-63248-057-6 doi: 10.15224/ 978-1-63248-057-6-100

\section{TABLE 1 SUMMARY OF RESULTS}

\begin{tabular}{|l|l|l|l|l|l|}
\hline $\begin{array}{l}\text { Leg } \begin{array}{l}\text { Inclinati } \\
\text { on Angle }\end{array} \\
\text { Weight }\end{array}$ & \multirow{2}{*}{$\begin{array}{l}\text { Initial } \\
\text { Wruss Analysis }\end{array}$} & $\begin{array}{l}\text { Mixed } \\
\text { Analysis }\end{array}$ \\
\cline { 3 - 6 } & & $\begin{array}{l}\text { Individu } \\
\text { al/ }\end{array}$ & $\begin{array}{l}\text { Groups } \\
\text { Member }\end{array}$ & $\begin{array}{l}\text { Individual/ } \\
\text { Singular } \\
\text { Weight }\end{array}$ & $\begin{array}{l}\text { Groups } \\
\text { Member } \\
\text { Weight }\end{array}$ \\
\hline Degree & $\mathrm{kg}$ & $\mathrm{kg}$ & $\mathrm{kg}$ & $\mathrm{kg}$ & $\mathrm{kg}$ \\
\hline $5^{\circ}$ & 22,000 & 10,759 & 17,945 & 10,871 & 18,366 \\
$10^{\circ}$ & 25,000 & 10,843 & 18,461 & 10,924 & 18,430 \\
$15^{\circ}$ & 30,000 & 11,441 & 19,681 & 11,525 & 19,650 \\
$20^{\circ}$ & 35,000 & 13,600 & 25,054 & 13,675 & 25,254 \\
$30^{\circ}$ & 65,000 & 24,961 & 52,235 & 25,044 & 52,425 \\
\hline
\end{tabular}

The graph in Fig. 11 indicate no significant weight increment when the leg tower angle lies from $5^{\circ}$ to $15^{\circ}$. The optimum weight of the Transmission Tower lies about $10^{\circ}$ after taken into consideration the deflection and foundation requirements.

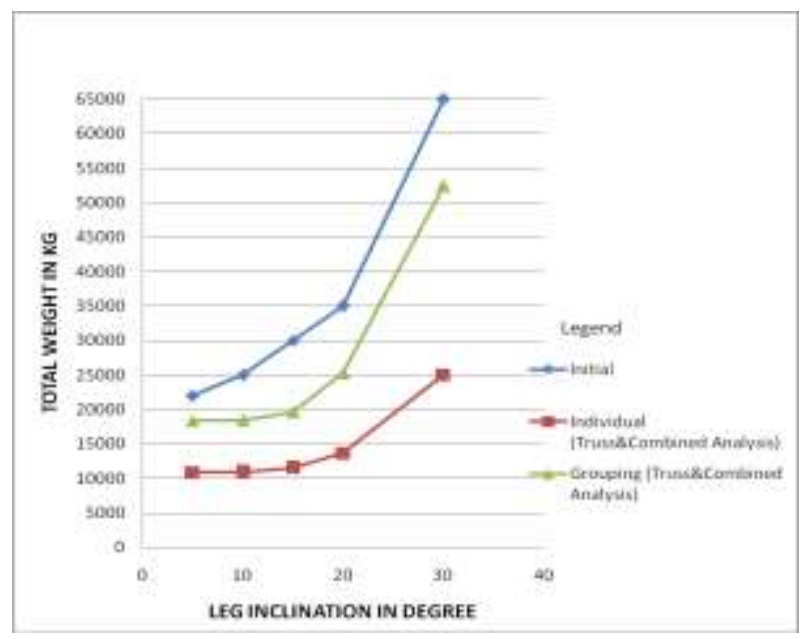

Figure 11 Total Tower Weights against Leg Inclination Angle

\section{v. Conclusions}

The shape algorithm and structural analysis strategies can be integrated simultaneously in design process of transmission tower to obtain the optimum design. The element groupings can be manipulated to achieve the minimum fabrication cost of the tower. Several combinations of group can be studied to get the optimum weight and fabrication cost of the tower. The shape algorithm is based on changing the inclination degree of the legs of the tower whilst two different structural analysis strategies are perform based on truss element or combined beam and truss element model or groups of member. Shape factors and structural analysis strategies play an. important role in the optimization process use in the design of the transmission tower.

- No significant weight saving is found between structural modelling strategy using truss and mixed truss-beam analysis.

- Optimum shape topography for optimum weight show an incline leg angle of about 10 degree. The optimum

weight using topographical algorithm obtained for this tower is $10,924 \mathrm{~kg}$ for singular members and $18,430 \mathrm{~kg}$ for element grouping.

- Beyond the $15^{\circ}$ leg angle, the total weight increases exponentially which is too expensive for the cost of the tower.

- The topographical algorithm is based on changing the inclination degree of the legs of the tower to obtain the optimum weight in the design and fabrication is viable to be used in the design.

- The topographical algorithm with optimized size, shape, and topology variables in the tower and was successfully integrated simultaneously with the structural modelling strategy using truss and mixed truss-beam analysis in the actual design of the tower.

\section{Acknowledgment}

The authors express their gratitude to Centre of Forensic Engineering of Civil Engineering Department, Universiti Tenaga Nasional, Malaysia who provided the data for this study.

\section{References}

[1] da Silva JGS, da S. Vellasco PCG, de Andrade SAL, de Oliveira MIR. Structural assessment of current design models for transmission and telecommunication towers. Journal of Constructional Steel Research 61 (2005) 1108-1134.

[2] Mikitarenko MA, Perelmuter AV. Safe fatigue life of steel towers under action of wind vibrations. Journal of Wind Engineering and Industrial Aerodynamics 1998;74-76:1091-100

[3] Rao GV. Optimum designs for transmission line towers. Computers and Structures 1995;57:85-92.

[4] Natarajan K. Santhakumar AR. Reliability-based optimization of transmission line towers. Computer and Structures 1995;55:387-403.

[5] Jasim NA, Galeb AG. Optimum design of square free standing communication towers. Journal of Constructional Steel Research. $58: 413$

[6] [das Nevas FDA, da Fonseca M. Simultaneous Sizing and Shape Optimization of Transmission Towers Using Genetic Algorithm, EngOpt 2008 - International Conference on Engineering Optimization. Rio de Janeiro, Brazil 1st -5th June 2008.

[7] M.P. Saka, Shape Optimization of Trusses. J Struc Div, ASCE 106(5), 1155-1174 (1980).

[8] G. N Vanderplaats, Numerical Methods for Shape Optimization - an assessement of the state of art. Proc. Int. Symp. Optimum Steel Design. Tuscon, AZ (1981).

[9] Rajan S.D Sizing, Shape and Topology Design Optimization of Trusses Using Genetic Algorithm. J. Struc. Engrg, ASCE 118(5),1233-1250 (1995)

[10] Z Che Muda et al Optimization of Structural Design for Sustainable Construction of Transmission Tower Based on Topographical Algorithm, IOP Conference Series ICEE2013: Earth and Environment Sciences. 16 (2013)

[11] Grierson DE. Knowledge-Based Expert System for Optimal Structural Design Proceeding of the NATO Advanced Study Institute on Optimization and Decision Support Systems in Civil Engineering Edinburgh U.K 25 June - 6 July 1989. Proceeding of the NATO Advanced Study Institute on Optimization and Decision Support Systems in Civil Engineering Edinburgh U.K 25 June - 6 July 1989

About Author (s):

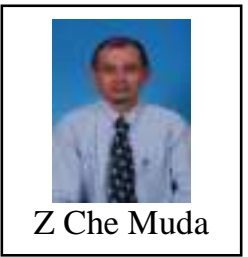

This paper look into an integrated design approach strategies whereby topographical factor is simultaneously integrated with the structural modelling strategy using truss and truss-beam analysis to obtain the optimum design of the transmission tower taking cognizance of the fabrication in its construction. 